\title{
Neurotrophic, Gene Regulation, and Cognitive Functions of Carboxypeptidase E-Neurotrophic Factor- $\alpha 1$ and Its Variants
}

OPEN ACCESS

Edited by:

Limei Zhang,

National Autonomous University of Mexico, Mexico

Reviewed by:

Illana Gozes,

Tel Aviv University, Israel Maite Montero-Hadjadje, Université de Rouen, France

${ }^{*}$ Correspondence: Y. Peng Loh lohp@mail.nih.gov

Specialty section:

This article was submitted to Neuroendocrine Science,

a section of the journal

Frontiers in Neuroscience

Received: 25 January 2019

Accepted: 01 March 2019

Published: 19 March 2019

Citation:

Xiao L, Yang X and Loh YP (2019)

Neurotrophic, Gene Regulation, and Cognitive Functions of Carboxypeptidase E-Neurotrophic

Factor- $\alpha 1$ and Its Variants.

Front. Neurosci. 13:243.

doi: 10.3389/fnins.2019.00243

\section{Lan Xiao, Xuyu Yang and Y. Peng Loh*}

Section on Cellular Neurobiology, Eunice Kennedy Shriver National Institute of Child Health and Human Development, National Institutes of Health, Bethesda, MD, United States

Carboxypeptidase E, also known as neurotrophic factor- $\alpha 1$ (CPE-NF $\alpha 1$ ), was first discovered as an exopeptidase and is known to work by cleaving C-terminal basic amino acids from prohormone intermediates to produce mature peptide hormones and neuropeptides in the endocrine and central nervous systems, respectively. CPE-NF $\alpha 1$ also plays a critical role in prohormone sorting and secretory vesicle transportation. Recently, emerging studies have indicated that CPE-NF $\alpha 1$ exerts multiple non-enzymatic physiological roles in maintaining normal central nervous system function and in neurodevelopment. This includes potent neuroprotective and anti-depressant activities, as well as stem cell differentiation functions. In addition, $\mathrm{N}$-terminal truncated variants of CPE-NF $\alpha 1$ have been identified to regulate expression of important neurodevelopmental genes. This mini-review summarizes recent advances in understanding the mechanisms underlying CPE-NF $\alpha 1$ 's function in neuroprotection during stress and aspects of neurodevelopment.

Keywords: neuroprotection, neurotrophic factor, hippocampus, neurodevelopment, FGF2, BCL2, WNT/betacatenin, stress

\section{INTRODUCTION}

CPE-NF $\alpha 1$, a member of the M14 metallocarboxypeptidase family was discovered in 1982 in bovine adrenal medulla and named as enkephalin convertase due to its enzymatic activity in processing enkephalin precursor into its mature form (Fricker and Snyder, 1983). Since then, CPE-NF $\alpha 1$ has been shown to cleave $\mathrm{C}$-terminal basic amino acids from the intermediates generated by proprotein convertases' action on prohormones, thereby producing bioactive hormones and neuropeptides (Hook et al., 1982; Fricker and Snyder, 1983; Fricker, 1988). In the central nervous system, CPE$\mathrm{NF} \alpha 1$ also functions as a regulated secretory pathway sorting receptor, secretory vesicle transport regulator and mediates synaptic vesicle localization to the active zone for release (Cawley et al., 2012; Ji et al., 2017). Recent studies have indicated that CPE-NF $\alpha 1$ is a new neurotrophic factor functioning extracellularly, independent of its enzymatic activity, in the adult and embryonic central nervous system (Ji et al., 2017). Human mutations of CPE-NF 1 have been associated with obesity, diabetes, infertility, learning disabilities, and Alzheimer's disease (AD) (Alsters et al., 2015; Cheng et al., 2016a). This review presents recent advances concerning the molecular structure, 
distribution, and multifunctional roles of CPE-NF $\alpha 1$ and its variants in the central nervous system in health and disease.

\section{MOLECULAR STRUCTURE AND BIOSYNTHESIS OF CPE-NF $\alpha 1$ AND ITS VARIANTS}

In mammals, WT-CPE-NF $\alpha 1$ gene consists of nine exons and encodes a 476 amino acid polypeptide (Jung et al., 1991; Cawley et al., 2012). Two CPE-NF $\alpha 1$ mRNA transcripts, 2.4 and $1.7 \mathrm{~kb}$ in size, respectively, have been identified by Northern Blot analysis and DNA sequencing from human cancer cells. The $2.4 \mathrm{~kb} C P E-$ $\mathrm{NF} \alpha 1$ transcript encodes a $53 \mathrm{kD}$ WT-CPE/NF $\alpha 1$ and the $1.7 \mathrm{~kb}$ transcript encodes an N-terminal truncated $40 \mathrm{kD}$ CPE-NF $\alpha 1$ due to the intra-exonic splicing in exon1 (Yang et al., 2017). Both transcripts have also been detected in Northern blot of human hippocampal mRNA extract (Yang, our unpublished data). Three $\mathrm{CPE}-\mathrm{NF} \alpha 1$ transcripts, a $2.3 \mathrm{~kb}$ WT transcript and two CPE$\mathrm{NF} \alpha 1 \mathrm{mRNA}$ variants, 1.9 and $1.73 \mathrm{~kb}$ in size (Figure 1) have been identified in mouse embryonic brain. Unlike in human cancer cells, the two mouse CPE-NF $\alpha 1$ mRNA variants are generated by using alternative transcription start sites, each of them encodes an N-terminal truncated $\mathrm{CPE}-\mathrm{NF} \alpha 1$ with a molecular weight of 47 and $40 \mathrm{kD}$, respectively (Yang et al., 2017; Xiao et al., 2018).

The CPE-NF $\alpha 1$ protein consists of a signal peptide, a catalytic domain, and a C-terminal domain. A 3-D structure model of $\mathrm{CPE}-\mathrm{NF} \alpha 1$ shows a zinc binding site in the enzymatic domain, a prohormone sorting signal binding site, an amphipathic $\alpha$-helical transmembrane domain, and a cytoplasmic tail that interacts with microtubule proteins for vesicle transport (Cawley et al., 2012). Mature CPE-NF $\alpha 1$ has 476 -amino acids. It is synthesized as preproCPE-NF $\alpha 1$ that has a 25 -amino acid signal peptide located at the $\mathrm{N}$-terminal that directs proCPE-NF $\alpha 1$ to the cisternae of the rough endoplasmic reticulum (ER) where it is removed (Figure 2). The proCPE-NF $\alpha 1$ is then transported to the granules of the regulated secretory pathway through the Golgi complex where 17-amino acids comprising the pro-region are removed (Song and Fricker, 1995). Further processing at Arg455Lysine 456 (Fricker and Devi, 1993) in the secretory granules yields a soluble form of CPE-NFa1 $(50 \mathrm{kDa})$, while the $53 \mathrm{kD}$ unprocessed form is associated with the granule membrane, with some molecules assuming a transmembrane orientation (Cawley et al., 2012).

\section{DISTRIBUTION OF CPE-NF $\alpha 1$ AND CPE-NF $\alpha 1-\Delta N$}

In mammals, CPE-NFa1 is generally distributed in the endocrine and nervous system, with the highest concentration in the brain (Strittmatter et al., 1984). Immunohistochemical studies showed $\mathrm{CPE}-\mathrm{NF} \alpha 1$ is located in neuropeptide-rich regions of the brain and endocrine system, for example, in the hypothalamus, pituitary, adrenal medulla, paraventricular nucleus, hippocampus, and amygdala (Hook et al., 1985; Lynch et al., 1990). Consistently, CPE-NF 1 mRNA is also found to be highly expressed in these brain regions (Birch et al., 1990; MacCumber et al., 1990; Zheng et al., 1994). The retina and olfactory bulb are also highly enriched in $\mathrm{CPE}-\mathrm{NF} \alpha 1$ (Zhu et al., 2005). In the retina, $\mathrm{CPE}-\mathrm{NF} \alpha 1$ is localized to the photoreceptors and is involved in synaptic transmission to the inner retina (Zhu et al., 2005). At the cellular level, $\mathrm{CPE}-\mathrm{NF} \alpha 1$ is mainly distributed in the trans-Golgi network and dense core secretory granules of endocrine cells and peptidergic neurons (Cawley et al., 2012). CPE-NF $\alpha 1$ exists as two active forms, the soluble and membrane form (Figure 2). The soluble form of CPE-NFa1 functions as an enzyme that cleaves C-terminal basic residues such as arginine and lysine from intermediates derived from neuropeptide precursors or prohormones to produce biologically active peptides or hormones. The membrane form of CPE-NF $\alpha 1$ acts as a sorting receptor at the trans-Golgi network to direct prohormones to the regulated secretory pathway granules, and mediates secretory granule movement (Cawley et al., 2012). In contrast, the N-terminal truncated (CPE-NF $\alpha 1-\Delta N$ ) forms which lack a signal peptide do not enter the secretory pathway. The $40 \mathrm{kD}$ form of CPE-NF $\alpha 1-\Delta \mathrm{N}$ has been shown to be localized in the cytoplasm and to be able to translocate into the nucleus where it exerts its effects on gene regulation (Qin et al., 2014) (see summary in Table 1).

\section{MICE AND HUMANS WITH CPE-NF $\alpha 1$ MUTATION EXHIBIT NEUROLOGICAL DEFICITS}

$\mathrm{CPE}-\mathrm{NF} \alpha 1$ knockout (KO) mice, in addition to exhibiting endocrinological deficits such as obesity, diabetes, and infertility due to lack of enzyme activity, display a variety of behavioral abnormalities as evidenced by deficits in learning and memory in Morris water maze, object preference, and social transmission of food preference tests (Woronowicz et al., 2008). They also display depressive-like behavior (Cheng et al., 2015, 2016a). $\mathrm{CPE}^{\mathrm{fat} / \mathrm{fat}}$ mice which have a Ser202Pro mutation and lack CPE$\mathrm{NF} \alpha 1$ have a similar phenotype to the knockout mouse and exhibit anxiety-like and depression-like behaviors (Rodriguiz et al., 2013). Interestingly, a human with a null mutation also demonstrated similar symptoms, such as obesity, diabetes, hypogonadotropic hypogonadism, and impaired intellectual ability (Alsters et al., 2015). In another study, a human mutation of $\mathrm{CPE}-\mathrm{NF} \alpha 1$ with three adenosines insertions was identified, this mutation was named QQ-CPE-NF 1 . Mice bearing this mutation showed neurodegeneration in the hippocampus and prefrontal cortex, deficits in neurogenesis at the dentate gyrus and hyperphosphorylation of tau (Cheng et al., 2016a). Another human CPE-NFa1 mutation, T980C, which introduces a W235R change in the catalytic domain of $\mathrm{CPE}-\mathrm{NF} \alpha 1$ caused a loss of enzyme activity, neurotoxic accumulation in the ER, resulting in ER stress and cell death when overexpressed in Neuro 2A cells. This novel single nucleotide polymorphism in the CPE$\mathrm{NF} \alpha 1$ gene found in $12.5 \%$ of the AGI_ASP population may confer neurological disorders in humans (Cong et al., 2017). These observations suggest that $\mathrm{CPE}-\mathrm{NF} \alpha 1$ plays an important 


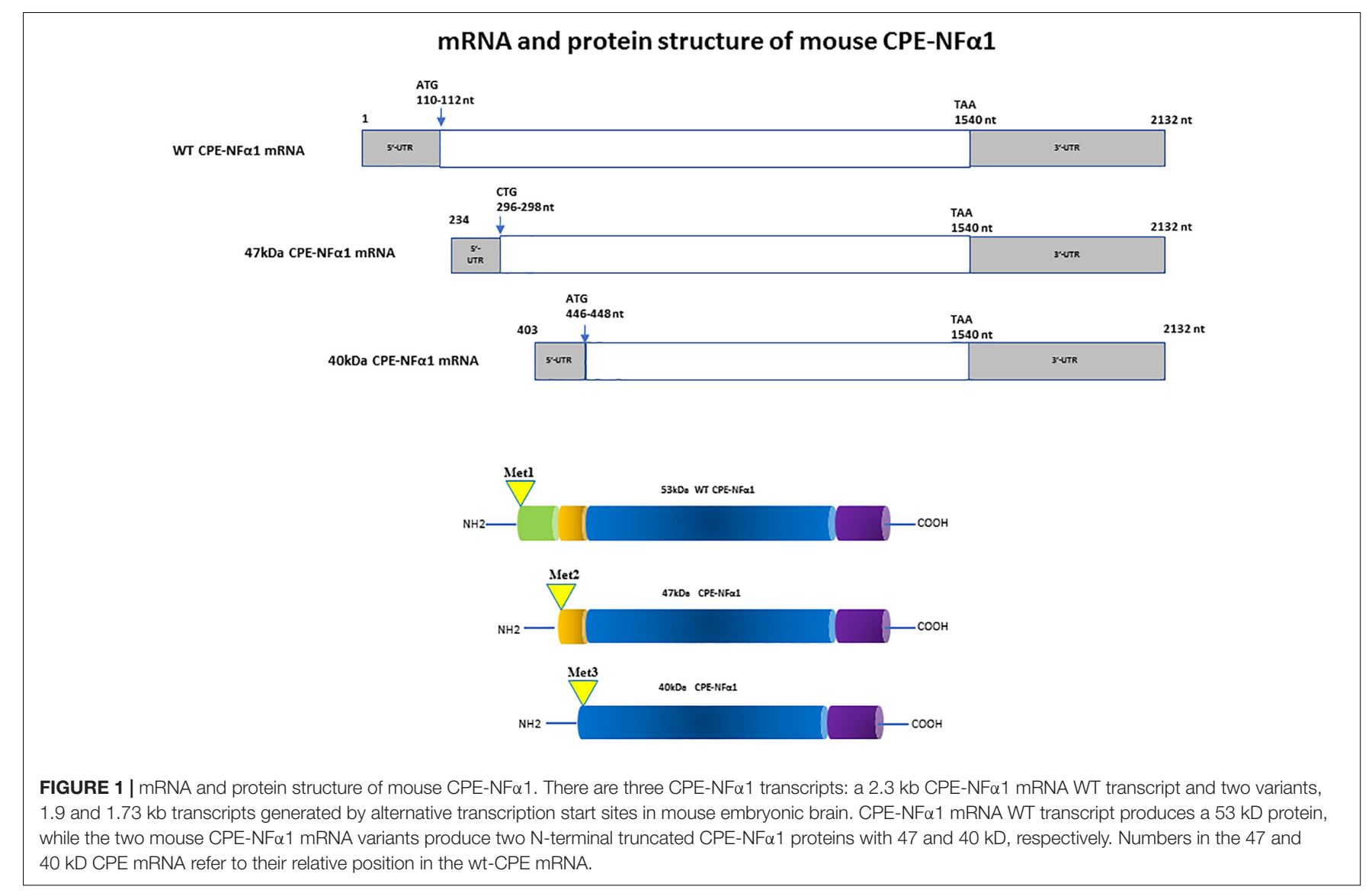

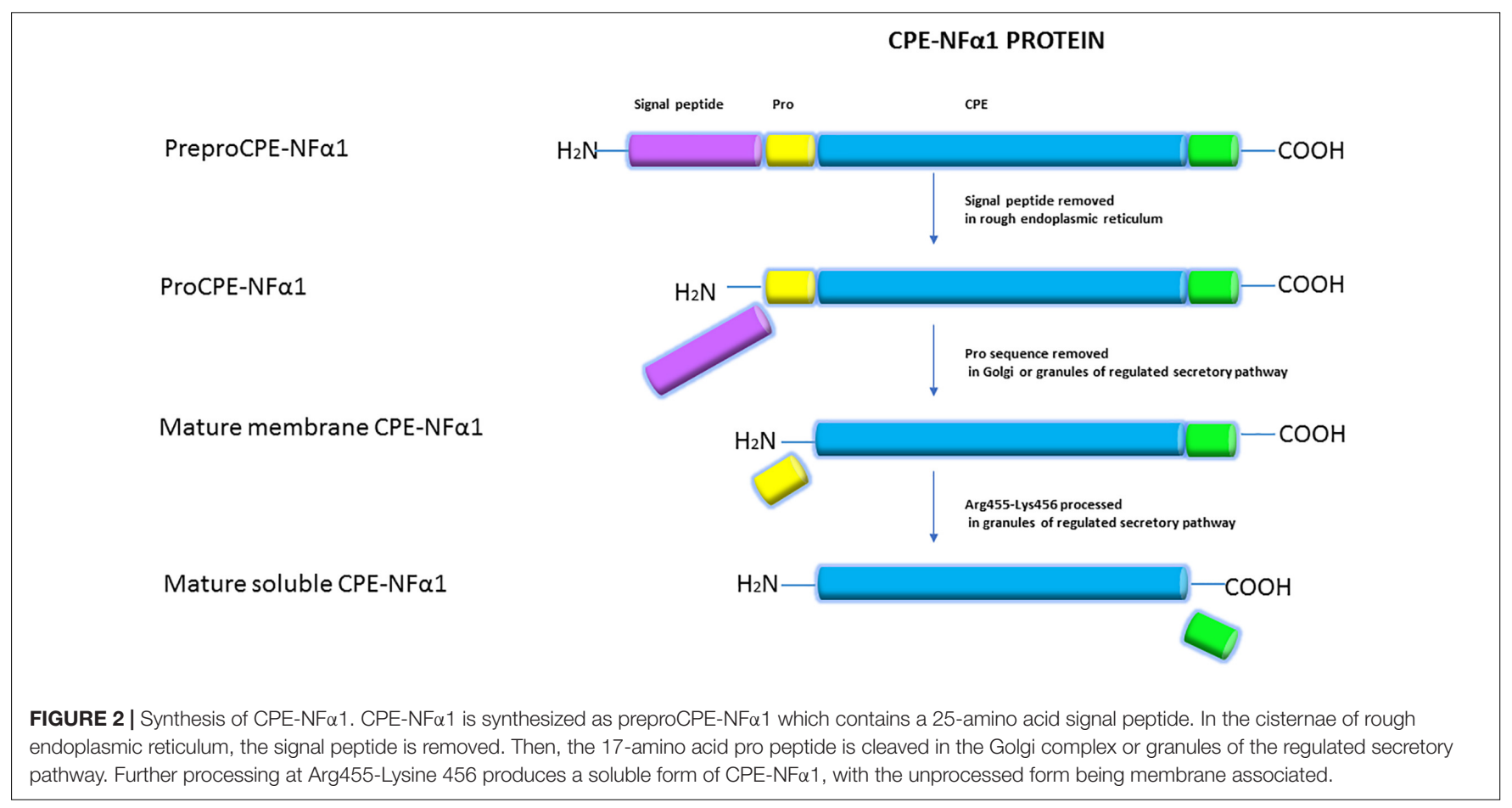


role in neurological function, and mutation of this gene can lead to cognitive and neurodegenerative disorders.

\section{CPE-NF $\alpha 1$ IN NEURODEGENERATIVE DISORDERS AND STRESS}

In the cerebral cortex of $\mathrm{AD}$ patients, an abnormal accumulation of CPE-NF $\alpha 1$ was detected in dystrophic neurites surrounding amyloid plaques (Pla et al., 2013). In an AD animal model of APPswe/PS1dE9 mice, similar pattern of changes were also found. Amyloid plaques were surrounded by aberrant accumulation of CPE-NF $\alpha 1$ and Secretogranin III (SgIII) (Pla et al., 2013). Peptidase activity analysis of the postmortem brain from $\mathrm{AD}$ patients showed that soluble enzymatic activity of $\mathrm{CPE}-\mathrm{NF} \alpha 1$ was significantly increased in the Brodmann Area 21 compared with control (Weber et al., 1992). In a Cathepsins B and L double knockout mouse model that demonstrated early-onset neurodegeneration and reduction in brain size, the expression of $\mathrm{CPE}-\mathrm{NF} \alpha 1$ was upregulated by 10-fold (Stahl et al., 2007). In experimental autoimmune encephalomyelitis (EAE) animal model, CPE-NF $\alpha 1$ has been mapped as a EAE-linked trait loci which is associated to the severity of the disease and shown to be downregulated (Ibrahim et al., 2001; Mazon Pelaez et al., 2005). These observations suggest that $\mathrm{CPE}-\mathrm{NF} \alpha 1$ is associated to the pathophysiology of neurodegenerative diseases.

Studies have shown that $\mathrm{CPE}-\mathrm{NF} \alpha 1$ expression is up-regulated after different types of stress. CPE-NF $\alpha 1 \mathrm{mRNA}$ and protein were both increased in the rat hippocampal CA1, CA3, and cortex regions $15 \mathrm{~min}$ after transient global ischemia followed by $8 \mathrm{~h}$ reperfusion (Jin et al., 2001). An accumulation of CPE$\mathrm{NF} \alpha 1$ precursor was found in mouse cortex after focal cerebral ischemia in vivo and in ischemic cortical neurons in vitro.

TABLE 1 | Comparison of CPE-NF $\alpha 1 \mathrm{WT}$ and CPE-NF $\alpha 1-\Delta \mathrm{N}$.

\begin{tabular}{|c|c|c|}
\hline & CPE-NF $\alpha 1 \mathrm{WT}$ & CPE-NF $\alpha 1-\Delta N$ \\
\hline Biosynthesis & $\begin{array}{l}\text { First transcription start } \\
\text { site }\end{array}$ & $\begin{array}{l}\text { Alternative transcription } \\
\text { start sites }\end{array}$ \\
\hline Intracellular location & $\begin{array}{l}\text { Regulated secretory } \\
\text { vesicles }\end{array}$ & Cytoplasm and nucleus \\
\hline Distribution & $\begin{array}{l}\text { Endocrine and CNS. } \\
\text { Embryonic and adult } \\
\text { brain }\end{array}$ & $\begin{array}{l}\text { Embryonic, not adult } \\
\text { brain in mouse }\end{array}$ \\
\hline $\begin{array}{l}\text { Soluble and membrane } \\
\text { forms }\end{array}$ & $\begin{array}{l}\text { Soluble and membrane } \\
\text { associated }\end{array}$ & Soluble \\
\hline Extracellular secretion & $\begin{array}{l}\text { Secreted from vesicles to } \\
\text { extracellular space }\end{array}$ & Not secreted \\
\hline Signal peptide & Yes & No \\
\hline Structure & - & Lacking N-terminal \\
\hline Enzymatic activity & Yes & Weak enzymatic activity \\
\hline $\begin{array}{l}\text { Intracellular sorting receptor } \\
\text { to regulatory secreted } \\
\text { pathway }\end{array}$ & Yes & No \\
\hline $\begin{array}{l}\text { Facilitates vesicle trafficking } \\
\text { via cytoplasmic tail }\end{array}$ & Yes & No \\
\hline
\end{tabular}

Vice versa, mice lacking $\mathrm{CPE}-\mathrm{NF} \alpha 1$ were more vulnerable to focal cerebral ischemia (Zhou et al., 2004). Stress such as cat odor upregulated $\mathrm{CPE}-\mathrm{NF} \alpha 1$ gene expression in rat amygdala (Koks et al., 2004). Mild chronic restraint stress for 7 days upregulated CPE-NF $\alpha 1$ expression in mouse hippocampal CA3 region (Murthy et al., 2013). Reduced levels of CPE-NF 1 were found in the offspring of pregnant ewes that experienced aversive interaction with human handling, along with abnormal corticolimbic dendritic spine morphology (Coulon et al., 2013). Primary cultured hippocampal neurons derived from CPENF $\alpha 1-K O$ mice tend to die more rapidly than that from wild type (WT) mice (Cheng et al., 2013). Low-potassium-induced apoptosis in cultured primary cerebellar granule neurons from $\mathrm{CPE}-\mathrm{NF} \alpha 1^{+/-}$mice are much higher than that from CPE$\mathrm{NF} \alpha 1^{+/+}$mice (Koshimizu et al., 2009). Overexpression of CPE$\mathrm{NF} \alpha 1$ in rat primary hippocampal neurons prevented hydrogen peroxide-induced neurotoxicity (Woronowicz et al., 2008). All these studies indicate that stress modulates $\mathrm{CPE}-\mathrm{NF} \alpha 1$ expression in the central nervous system (CNS).

\section{CPE-NF $\alpha 1$ AS A NEUROTROPHIC FACTOR IN NEUROPROTECTION AND ANTI-DEPRESSION}

CPE-NF $\alpha 1$ plays multiple intracellular roles in the CNS independent of its enzymatic activity. It functions as a regulated secretory pathway sorting receptor for proneuropeptides (Cool et al., 1997) and proBDNF (Lou et al., 2005), mediates anterograde transport of neuropeptide and BDNF vesicles to the plasma membrane via cytoplasmic tail interaction with dynactin/dynein (Park et al., 2008), and localizes synaptic vesicles to the actin-rich pre-active zone in hypothalamic neurons through actin binding protein $\gamma$-adducin (Lou et al., 2010). While the mechanisms underlying these cell biological actions of $\mathrm{CPE}-\mathrm{NF} \alpha 1$ are well understood, those governing the neuroprotective effects of CPE-NF $\alpha 1$ during stress are just emerging. In 2013, a study showed that CPE-NF $\alpha 1$ secreted from hippocampal neurons, acts as a neuroprotective factor extracellularly, independent of its enzymatic activity (Cheng et al., 2013). Secreted rat WT CPE-NF $\alpha 1$ and CPE-NF $\alpha 1-E 300 Q$ (mutant form with no enzymatic activity) (Qian et al., 1999) in medium from transduced cultured primary rat hippocampal neurons protected them from cell death induced by $\mathrm{H}_{2} \mathrm{O}_{2}$ mediated oxidative stress and glutamate excitotoxicity. Results from experiments with recombinant WT CPE-NF $\alpha 1$ or CPENFo1-E342Q (mouse homolog of E300Q) demonstrated similar effects. In addition, hippocampal neurons from CPE-NF $\alpha 1-\mathrm{KO}$ mice at embryonic day 17 (E17) in culture exhibited higher death rate than WT E17 neurons, and this was reversed by treatment with recombinant WT CPE-NF $\alpha 1$ (Cheng et al., 2013). Studies on the mechanism underlying the neuroprotective action of CPE$\mathrm{NF} \alpha 1$ using rat primary hippocampal neurons in culture revealed that when these cells were stressed with $\mathrm{H}_{2} \mathrm{O}_{2}$, it activated the ERK and AKT signaling pathways, presumably by binding to a cognate receptor, which then up-regulated expression of $\mathrm{Bcl} 2$, a pro-survival mitochondrial protein, and down-regulated 

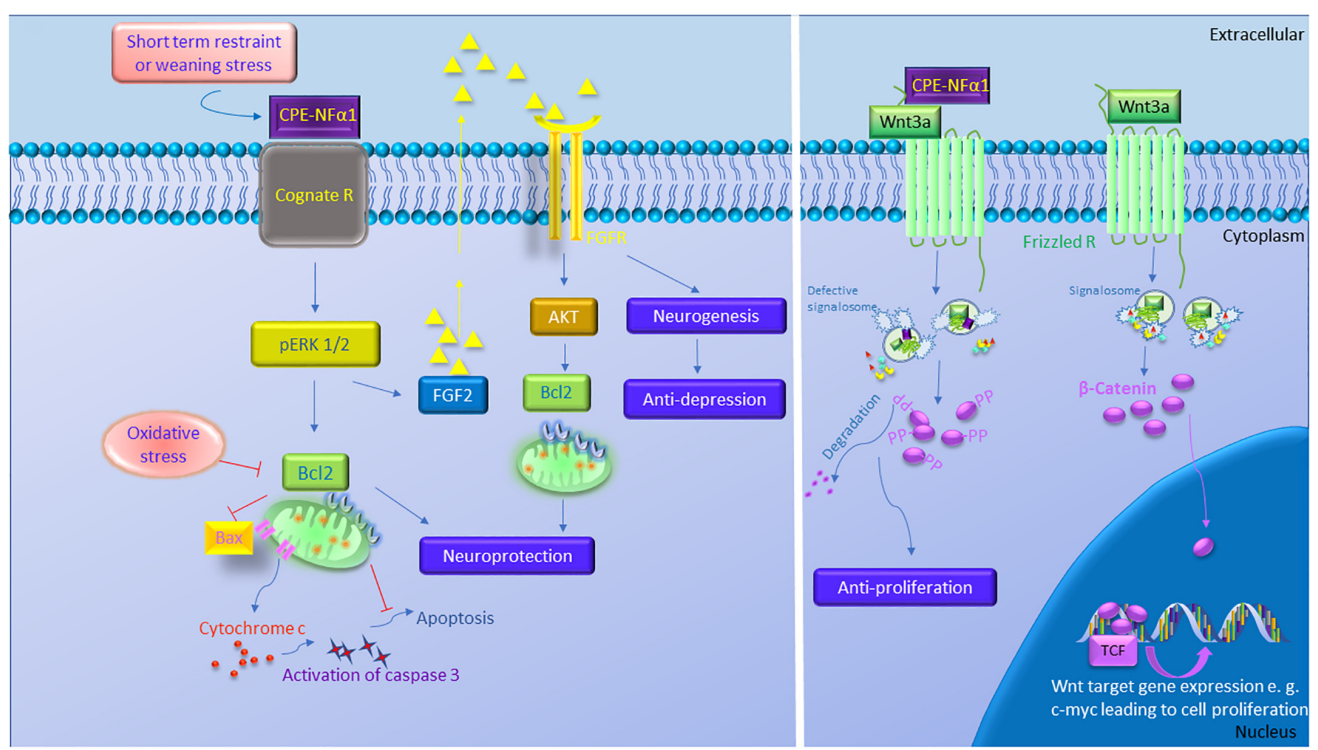

FIGURE 3 | The multiple functions of CPE-NF $\alpha 1$ in the central nervous system (CNS). CPE-NF 1 plays multiple functions in the CNS independent of its enzymatic activity. Short term restraint or weaning stress increases CPE-NF $\alpha 1$ which binds to a cognate receptor and upregulates ERK1/2 and Bcl2, and decreases Bax and cytochrome c-induced activation of caspase 3 and apoptosis. CPE-NF $\alpha 1$ also increases FGF2 that activates AKT and Bcl2 signaling and increases hippocampal neurogenesis and produces antidepressive-like effect. CPE-NF $\alpha 1$ can also bind to Frizzled receptor - Wnt3a complex, enters the endosome that contains Wnt signaling factors and subsequently impairs the formation of signalosome. This results in $\beta$-catenin being degraded, rather than translocation into the nucleus and binds to T-cell factor transcription factor (TCF) to activate expression of Wnt target genes. Signalosome $\square$ Wnt

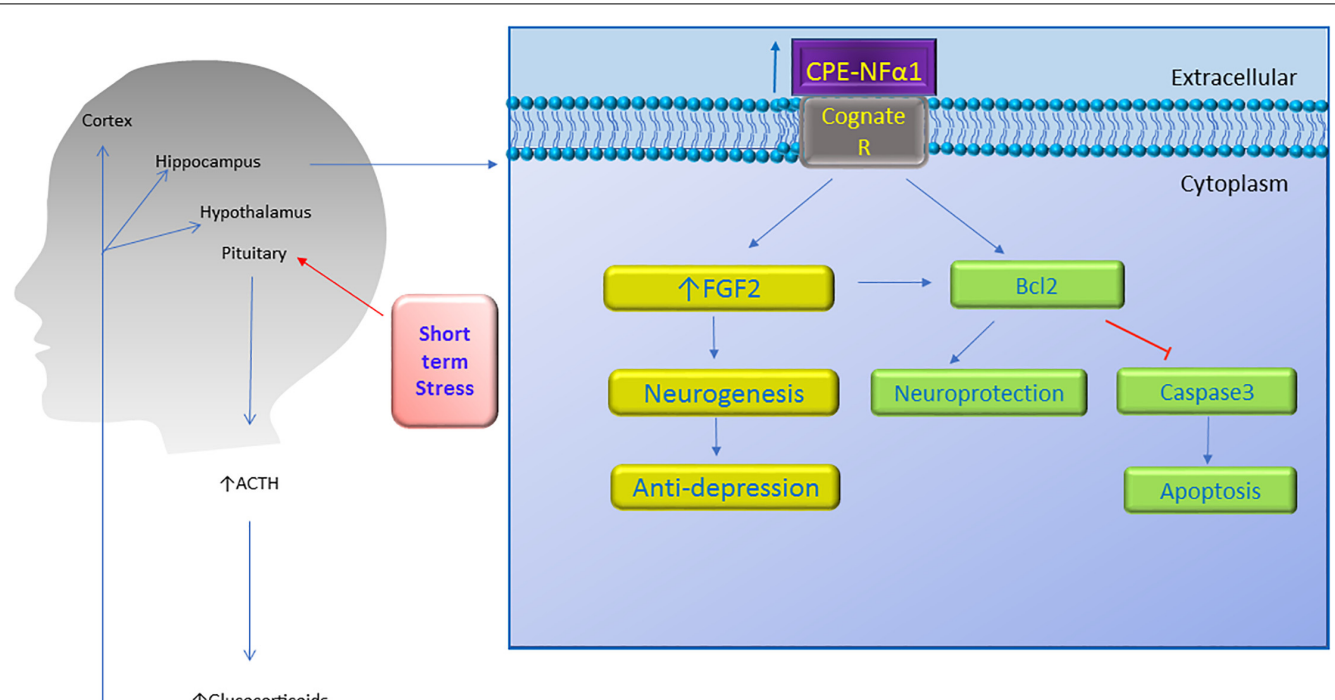

FIGURE 4 | Neuroprotective effect of CPE-NF $\alpha 1$. Short term stress activates the hypothalamic-pituitary-adrenal axis which then increases ACTH and glucocorticoid secretion. The glucocorticoids upregulate CPE-NF $\alpha 1$ expression via glucocorticoid regulatory elements (GRE) on the promoter. CPE-NF 1 is secreted and possibly activates its cognate receptor which then produces antidepressant-like effects via increasing FGF2 expression and neurogenesis in the hippocampus. Additionally, CPE-NF $\alpha 1$ protects against neurodegeneration through upregulating $\mathrm{Bcl} 2$, a mitochondrial pro-survival protein, by inhibiting caspase 3-mediated apoptosis.

expression of Caspase 3 to mediate neuroprotection (Cheng et al., 2013) (see Figure 3).

In an in vivo mouse model, complete degeneration of hippocampal CA3 region was observed in CPE-NF $1-\mathrm{KO}$ mice at 4 -weeks of age after weaning stress which included maternal separation, ear tagging, and tail snipping at 3 weeks of age (Woronowicz et al., 2008). CPE-NFa1-KO mice that were not subjected to the weaning process at 3 weeks of age showed no degeneration of the CA3 region examined at week 4 , indicating that this neurodegeneration was not due to a neurodevelopmental defect. Treatment with oral carbamazepine at $50 \mathrm{mg} / \mathrm{kg}$ daily for 2 weeks beginning at 2 weeks of age 


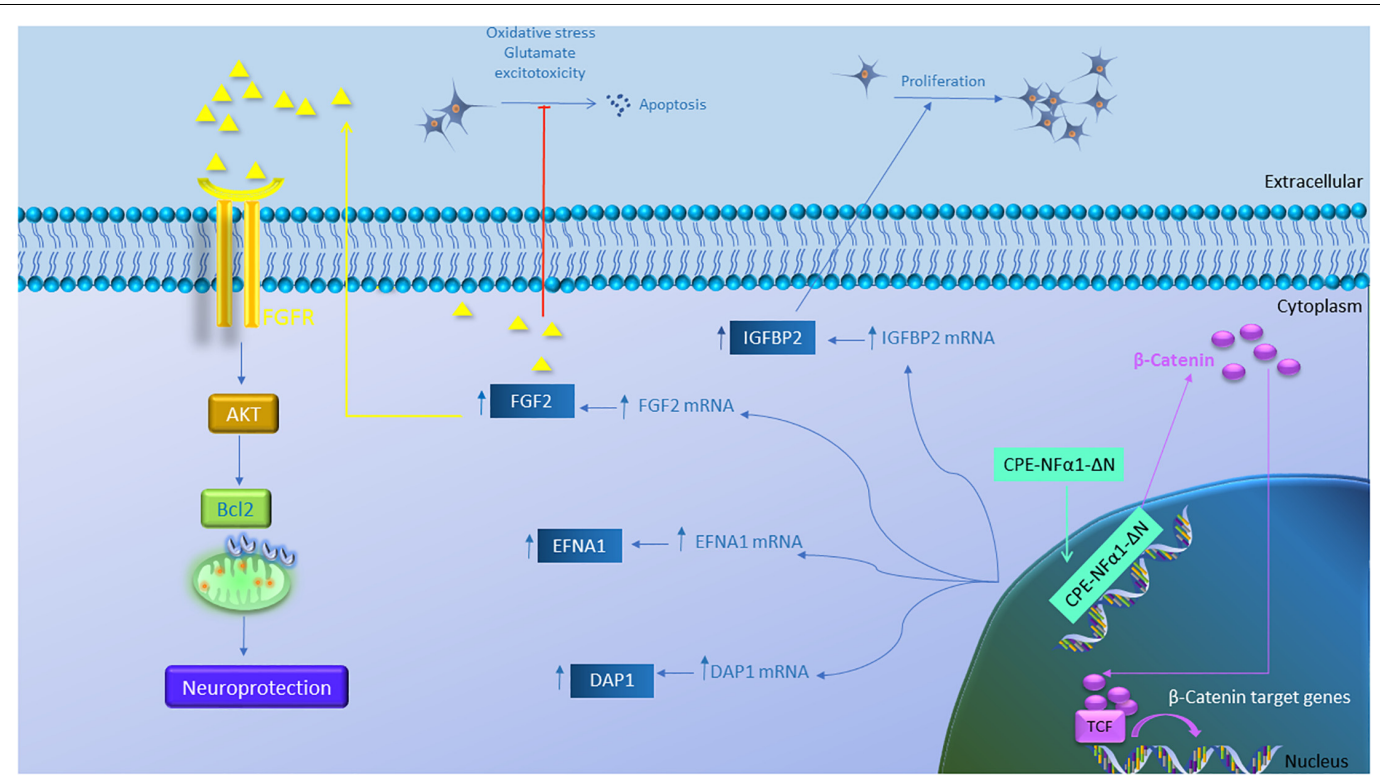

FIGURE 5 | Gene regulation function of CPE-NF $\alpha 1-\Delta \mathrm{N}$ in mouse embryonic neurons. CPE-NF $\alpha 1-\Delta \mathrm{N}$ increases expression of FGF2, IGFBP2, EFNA1, and DAP1 in mouse embryonic cortical and hippocampal neurons. IGFBP2 promotes neuronal proliferation while FGF2 inhibits oxidative stress or glutamate-induced excitotoxicity. FGF2 binds its receptor and induces neuroprotective effects via activating the AKT and Bcl2 signaling cascade. CPE-NF $\alpha 1-\Delta \mathrm{N}$ expressed in hippocampal neurons translocates into the nucleus and upregulates $\beta$-catenin expression. $\beta$-catenin then enters the nucleus and binds to T-cell factor (TCF) transcription factor to promote expression of Wnt target genes.

with the weaning process at 3 weeks of age, revealed no degeneration of the CA3 region when examined at 4 weeks of age (Woronowicz et al., 2012). These observations suggested that the CA3 pyramidal neurons underwent apoptosis due to glutamate excitotoxicity during the social and physical stress following the weaning protocol. In contrast, WT-mice, did not show any degeneration of the CA3 region after weaning stress. In another mouse model, adult $\mathrm{CPE}^{\text {fat/fat }}$ mice lacking $\mathrm{CPE}$ $\mathrm{NF} \alpha 1$, also showed degeneration of the CA3 region (Zhou, personal communication). These findings together with the in vitro studies (Cheng et al., 2013) support the hypothesis that $\mathrm{CPE}-\mathrm{NF} \alpha 1$ acts as a neurotrophic factor to protect the pyramidal neurons in the CA3 region in the hippocampus from stressinduced degeneration. Since BDNF is expressed in CPE-NF $\alpha 1$ KO mice (Xiao et al., 2017), yet they showed neurodegeneration after weaning, indicates that BDNF could not protect the CA3 neurons in lieu of CPE-NFa1. Further demonstration that $\mathrm{CPE}-\mathrm{NF} \alpha 1$ is a neuroprotective factor in vivo during stress came from studies showing that chronic restraint stress of mice for $1 \mathrm{~h}$ /day for 7 days resulted in an increase in CPE$\mathrm{NF} \alpha 1 \mathrm{mRNA}$ and protein expression in the hippocampus, with no evidence of neurodegeneration despite increased circulating corticosterone levels under this stress paradigm (Murthy et al., 2013). This up-regulation in expression of CPE-NF $\alpha 1$ concurrs with in vitro evidence showing that the CPE-NF $\alpha 1$ promoter has a glucocorticoid binding domain and that dexamethasone up-regulated the expression of CPE-NF $\alpha 1$ (Murthy et al., 2013). These mice also showed an increase in phosphorylation of Akt and $\mathrm{Bcl} 2$ expression; however, Bax, a pro-apoptotic mitochondria protein was decreased in the hippocampus (Murthy et al., 2013).
In contrast, $\mathrm{CPE}-\mathrm{NF} \alpha 1-\mathrm{KO}$ mice subjected to the same stress paradigm showed no change in Akt phosphorylation, a decrease in expression of $\mathrm{Bcl} 2$ protein and an increase in Bax protein in the hippocampus compared to WT mice (Murthy et al., 2013). In vitro and in vivo evidence taken together indicate that during emotional and physical stress, secretion of glucocorticoid increases CPE-NF $\alpha 1$ expression at the transcriptional and translational level in the hippocampus which in turn leads to neuroprotection of the CA1-3 neurons by acting extracellularly as a trophic factor to activate Erk or Akt signaling and increase $\mathrm{Bcl} 2$ pro-survival protein expression (see Figures 3, 4). CPE-NF $\alpha 1$ also up-regulates the expression of FGF2 (Cheng et al., 2015), which has been shown to mediate protection against amyloid beta- or glutamate-induced neurotoxicity in hippocampal or cortical neurons via the Akt-Bcl2 signaling pathway (Qin et al., 2014; Cheng et al., 2016b; Figures 3, 5).

Behavioral analysis revealed that the CPE-NF $\alpha 1-\mathrm{KO}$ and the $\mathrm{Cpe}^{\text {fat/fat }}$ mice exhibited depressive-like behavior as evidenced by increased immobility time in the forced-swimming test (Rodriguiz et al., 2013; Cheng et al., 2015). CPE-NF $\alpha 1-K O$ mice showed decreased levels of FGF2 (Cheng et al., 2015), a protein demonstrated to be decreased in post mortem brains of patients with major depressive disorder (Evans et al., 2004). In addition, after long-term chronic restraint stress, mice showed depressivelike behavior, and reduced $\mathrm{CPE}-\mathrm{NF} \alpha 1, \mathrm{FGF} 2$ and doublecortin, a marker for neuroblasts in their hippocampus. Interestingly, injection of $5 \mathrm{ng} / \mathrm{g}$ recombinant FGF2 into CPE-NF $\alpha 1-\mathrm{KO}$ mouse for 30 consecutive days completely reversed the decreased number of doublecortin positive neurons in the subgranular zone of hippocampus and depressive-like behaviors as evidenced by 
decreased immobility time in the forced-swim test (Cheng et al., 2015). In vitro studies showed that incubation of rat cultured hippocampal neurons with CPE-NF $\alpha 1$ enhanced FGF2 mRNA and protein expression which was inhibited by the Sp1 inhibitor mithramycin A, a transcription inhibitor actinomycin, and ERK inhibitor U0126, suggesting that CPE-NF $\alpha 1$ can upregulate FGF2 via ERK-Sp1 signaling cascade (Cheng et al., 2015). Thus, CPE$\mathrm{NF} \alpha 1$ may act as an anti-depressant through up-regulating FGF2 expression in the hippocampus.

\section{ROLE OF CPE-NF $\alpha 1$ AND CPE-NF $\alpha 1-\Delta N$ VARIANTS IN NEURODEVELOPMENT}

In mice and rats, CPE-NF $\alpha 1$ mRNA is expressed during embryogenesis as early as E5.5 mainly in the developing nervous system (Zheng et al., 1994; Selvaraj et al., 2017). In mice, the expression of CPE-NF $\alpha 1-\mathrm{WT}$ and the two CPE-NF $\alpha 1-\Delta \mathrm{N}$ transcripts were detected in E8.5 embryonic brain and their expression peaked at embryonic day (E) 10.5, then decreased from E12.5 to E16.5, and increased again at postnatal day 1 (P1). Interestingly, none of the CPE-NF $\alpha 1-\Delta \mathrm{N}$ mRNAs were found in adult mouse hippocampus or other organs such as liver, heart or lung, suggesting their critical role during embryonic neurodevelopment (Xiao et al., 2018). Studies of dendritic arborization in pyramidal layer $\mathrm{V}$ of cerebral cortex and hippocampal CA1 region in 14-week-old CPE-NF $\alpha 1-\mathrm{KO}$ mice revealed abnormal dendritic pruning and increased number of non-functional D-type spines (Woronowicz et al., 2010), suggesting a role of CPE-NF $\alpha 1$ in modeling the cytoarchitecture of the brain during development. Indeed, CPE-NF $\alpha 1$ has been shown to regulate NGF-induced neurite outgrowth via interacting with Wnt-3a and Wnt-5a in PC12 cells and mouse primary cortical neurons (Selvaraj et al., 2015). CPE-NF $\alpha 1$ is highly expressed in neural stem cells (Lee et al., 2012) and has been shown to inhibit embryonic neural stem cell proliferation by downregulating Wnt signaling pathway and $\beta$-catenin (Selvaraj et al., 2017). Studies have revealed that CPE-NF $\alpha 1$ forms a complex with Wnt3a ligand and Frizzled receptor to inhibit the Wnt3a signaling cascade (Figure 3; Skalka et al., 2013). Moreover, exogenous application of CPE-NF $\alpha 1$ and a nonenzymatic form of CPE-NF $\alpha 1(\mathrm{E} 300 \mathrm{Q})$ induced differentiation of E14.5 cortical neural stem cells into astrocytes via activating the ERK1/2-Sox9 signaling pathway to enhance glial fibrillary acidic protein (GFAP) expression (Selvaraj et al., 2017). This corroborates the $49 \%$ decrease in astrocyte numbers observed in the neocortex of mouse neonates in vivo at postnatal day 1 (P1). In another study, electroporation of CPE-NF $\alpha 1$ shRNA into E14.5 mouse embryos significantly decreased migration of neurons to cortex plate at E17.5, possibly due to the failure of transition from multipolar neurons into a bipolar morphology in the intermediate zone (Liang et al., 2018). Neuronal migration seems to depend on the function of the CPE-NFa1 cytoplasmic tail which can interact with dynactin, an adaptor protein that interacts with microtubules. Furthermore, this study also showed that $\mathrm{CPE}-\mathrm{NF} \alpha 1$ regulates dendrite morphology in vivo and in rat primary cultured hippocampal neurons (Liang et al., 2018).
While CPE-NF $\alpha 1$ acts extracellularly as an embryonic stem cell differentiation and anti-proliferation factor, studies have indicated that CPE-NF $\alpha 1-\Delta \mathrm{N}$ could serve as a master regulator of genes involved in neurodevelopment (Figure 5 and Table 2). $\mathrm{CPE}-\mathrm{NF} \alpha 1-\Delta \mathrm{N}$ (40 $\mathrm{kD}$ variant), but not CPE-NF $\alpha 1$ (Xiao, our unpublished data) was found to significantly up-regulate expression of four genes, fibroblast growth factor 2 (FGF2) (Qin et al., 2014), insulin-like growth factor binding protein2 (IGFBP2), death associated protein (DAP1), and EphrinA1 in HT22, a hippocampal cell line and in primary mouse cortical neurons (Xiao et al., 2018). These three genes are known to mediate neuronal proliferation, cell death and neuronal migration, respectively (Murphy et al., 1990; Deiss et al., 1995; Feinstein et al., 1995; Levy-Strumpf and Kimchi, 1998; Martinez et al., 2004; Martinez and Soriano, 2005; Russo et al., 2005; Zechel et al., 2010). Overexpressing of CPE-NF $\alpha 1-\Delta \mathrm{N}$ in HT22 cells promoted proliferation, but was inhibited by IGFBP2 siRNA, suggesting CPE-NF $\alpha 1-\Delta \mathrm{N}$ regulates embryonic neuronal proliferation through increasing IGFBP2. In addition, CPE$\mathrm{NF} \alpha 1-\Delta \mathrm{N}$-induced FGF2 expression has a neuroprotective role against glutamate and $\mathrm{H}_{2} \mathrm{O}_{2}$ neurotoxicity in rat embryonic cortical neurons (Qin et al., 2014). Since FGF2 is also known to play a role in neuronal proliferation and neurogenesis in the developing mouse cortex, $\mathrm{CPE}-\mathrm{NF} \alpha 1-\Delta \mathrm{N}$ may also regulate these events in the embryonic brain (Raballo et al., 2000). Moreover, CPE-NF $\alpha 1-\Delta \mathrm{N}$ has been shown to up-regulate the expression of $\beta$-catenin in the Wnt pathway in HEK-293 cells (Skalka et al., 2013) and osteosarcoma cell lines, which promoted migration of these cells (Fan et al., 2018). We have shown that neuroprotection by CPE-NF $\alpha 1-\Delta \mathrm{N}$ against glutamate excitotoxicity may also involve $\beta$-catenin and Wnt pathway. Glutamate treatment resulted in a decrease in $\beta$-catenin

TABLE 2 | Neuroprotective and neurodevelopmental functions of CPE-NF $\alpha 1$ WT and $\mathrm{CPE}-\mathrm{NF} \alpha 1-\Delta \mathrm{N}$.

\begin{tabular}{|c|c|c|}
\hline & Function & Reference \\
\hline \multirow[t]{7}{*}{ CPE-NF $\alpha 1 \mathrm{WT}$} & $\begin{array}{l}\text { Regulates NGF-induced neurite } \\
\text { outgrowth }\end{array}$ & Selvaraj et al., 2015 \\
\hline & Inhibits neuronal stem cell proliferation & Selvaraj et al., 2017 \\
\hline & $\begin{array}{l}\text { Induces differentiation of neural stem } \\
\text { cells into astrocytes }\end{array}$ & Selvaraj et al., 2017 \\
\hline & $\begin{array}{l}\text { Regulates cortical neuron migration and } \\
\text { dendrite arborization }\end{array}$ & Liang et al., 2018 \\
\hline & $\begin{array}{l}\text { Protects primary cultured rat } \\
\text { hippocampal neurons from } \\
\mathrm{H}_{2} \mathrm{O}_{2} \text {-induced oxidative stress }\end{array}$ & Cheng et al., 2013 \\
\hline & $\begin{array}{l}\text { CA3 completely degenerated after } \\
\text { weaning, ear tag and tail clipping at } \\
\text { 3-week of age and prevented by } \\
\text { carbamazepine }\end{array}$ & $\begin{array}{l}\text { Woronowicz et al., } \\
\text { 2008, } 2012\end{array}$ \\
\hline & $\begin{array}{l}\text { Upregulates FGF2 and produces } \\
\text { antidepressant-like effects }\end{array}$ & Cheng et al., 2015 \\
\hline \multirow[t]{2}{*}{$\begin{array}{l}\text { CPE-NF } \alpha 1-\Delta \mathrm{N} \\
(40 \mathrm{kD})\end{array}$} & $\begin{array}{l}\text { Protects primary rat embryonic cortical } \\
\text { neurons from glutamate and } \\
\mathrm{H}_{2} \mathrm{O}_{2} \text {-induced apoptosis via FGF2 }\end{array}$ & Qin et al., 2014 \\
\hline & $\begin{array}{l}\text { Increases proliferation via upregulating } \\
\text { IGFBP2 }\end{array}$ & Xiao et al., 2018 \\
\hline
\end{tabular}


level and poor cell viability compared to untreated control embryonic rat cortical neurons. However, in CPE-NF $\alpha 1-\Delta N-$ transduced neurons treated with glutamate, this decrease in $\beta$-catenin did not occur and the cell viability was similar to control. Treatment of cortical neurons with XAV939 which stimulates degradation of $\beta$-catenin (Huang et al., 2009) showed that in the presence of XAV939, the neuroprotective effect of $\mathrm{CPE}-\mathrm{NF} \alpha 1-\triangle \mathrm{N}$ against glutamate neurotoxicity was abolished. This suggests that the activation of the $\mathrm{Wnt} / \beta$-catenin pathway may also contribute to the neuroprotective mechanism of CPE$\mathrm{NF} \alpha 1-\Delta \mathrm{N}$ in embryonic neurons (Qin et al., our unpublished data). Additionally, $\beta$-catenin has been reported to mediate neuronal proliferation and differentiation of stem cells (Israsena et al., 2004). Thus, CPE-NF $\alpha 1-\Delta \mathrm{N}$ may also regulate these processes during development via the Wnt signaling pathway.

\section{CONCLUSION}

CPE-NF $\alpha 1$ is a multifunction protein (Table 2). In addition to being a prohormone and proneuropeptide processing enzyme, it is a sorting receptor and vesicle transport mediator. Recent studies have shown that it also plays a fundamental role in neurodevelopment, neurodegeneration, and cognitive functions. Null mutation of CPE-NF $\alpha 1$ in animal models and a human both produced similar deficits, including obesity, diabetes, and compromised cognitive function and memory. In addition, abnormal accumulation in the ER of a human mutant of CPE$\mathrm{NF} \alpha 1$ from an $\mathrm{AD}$ patient was found which caused neurotoxicity, neurodegeneration, and cognitive impairment in an animal model. In vitro studies using primary neurons in culture indicate that $\mathrm{CPE}-\mathrm{NF} \alpha 1$ acts extracellularly as a trophic factor, independent of enzymatic activity to mediate neuroprotection via activating several pro-survival signaling cascades such as upregulating $\mathrm{Bcl} 2$ and FGF2 signaling. Studies to demonstrate the neurotrophic effect in vivo will be necessary using transgenic

\section{REFERENCES}

Alsters, S. I., Goldstone, A. P., Buxton, J. L., Zekavati, A., Sosinsky, A., Yiorkas, A. M., et al. (2015). Truncating Homozygous Mutation of Carboxypeptidase $\mathrm{E}$ (CPE) in a morbidly obese female with type 2 diabetes mellitus, intellectual disability and hypogonadotrophic hypogonadism. PLoS One 10:e131417. doi: 10.1371/journal.pone.0131417

Birch, N. P., Rodriguez, C., Dixon, J. E., and Mezey, E. (1990). Distribution of carboxypeptidase $\mathrm{H}$ messenger RNA in rat brain using in situ hybridization histochemistry: implications for neuropeptide biosynthesis. Brain Res. Mol. Brain Res. 7, 53-59. doi: 10.1016/0169-328X(90)90073-M

Cawley, N. X., Wetsel, W. C., Murthy, S. R., Park, J. J., Pacak, K., and Loh, Y. P. (2012). New roles of carboxypeptidase $\mathrm{E}$ in endocrine and neural function and cancer. Endocr. Rev. 33, 216-253. doi: 10.1210/er.2011-1039

Cheng, Y., Cawley, N. X., and Loh, Y. P. (2013). Carboxypeptidase E/NFalpha1: a new neurotrophic factor against oxidative stress-induced apoptotic cell death mediated by ERK and PI3-K/AKT pathways. PLoS One 8:e71578. doi: 10.1371/ journal.pone.0071578

Cheng, Y., Cawley, N. X., Yanik, T., Murthy, S. R., Liu, C., Kasikci, F., et al. (2016a). A human carboxypeptidase E/NF-alphal gene mutation in an Alzheimer's disease patient leads to dementia and depression in mice. Transl. Psychiatry 6:e973. doi: 10.1038/tp.2016.237 mouse models to further support this hypothesis. Additionally, identifying a membrane receptor for CPE-NFa1 will be required to substantiate a receptor-mediated mechanism for activating signaling pathways for neuroprotection and stem cell differentiation. Furthermore, CPE-NF $\alpha 1$ and its derived peptides can be developed as potential therapeutic agents to treat neurodegenerative diseases. The $40 \mathrm{kD} C P E-N F \alpha 1-\Delta \mathrm{N}$ variant has been shown to activate genes involved in neurodevelopment (Table 2). Further studies will be required to determine the precise molecular mechanism underlying CPE-NF $\alpha 1-\Delta$ N's role in activating such genes during embryonic development.

\section{DATA AVAILABILITY}

The datasets generated for this study are available on request to the corresponding author.

\section{AUTHOR CONTRIBUTIONS}

All authors listed have made a substantial, direct and intellectual contribution to the work, and approved it for publication.

\section{FUNDING}

This research was supported by the Intramural Research Program of the Eunice Kennedy Shriver National Institute of Child Health and Human Development (NICHD), National Institutes of Health, United States.

\section{ACKNOWLEDGMENTS}

We thank Drs. Hong Lou, Vinay Sharma, and Sangeetha Hareendran, (NICHD) for helpful discussions of the manuscript.

Cheng, Y., Li, Z., Kardami, E., and Loh, Y. P. (2016b). Neuroprotective effects of LMW and HMW FGF2 against amyloid beta toxicity in primary cultured hippocampal neurons. Neurosci. Lett. 632, 109-113. doi: 10.1016/j.neulet.2016. 08.031

Cheng, Y., Rodriguiz, R. M., Murthy, S. R., Senatorov, V., Thouennon, E., Cawley, N. X., et al. (2015). Neurotrophic factor-alphal prevents stressinduced depression through enhancement of neurogenesis and is activated by rosiglitazone. Mol. Psychiatry 20, 744-754. doi: 10.1038/mp.2014.136

Cong, L., Cheng, Y., Cawley, N. X., Murthy, S. R., and Loh, Y. P. (2017). A novel single nucleotide T980C polymorphism in the human carboxypeptidase E gene results in loss of neuroprotective function. PLoS One 12:e170169. doi: 10.1371/ journal.pone.0170169

Cool, D. R., Normant, E., Shen, F., Chen, H. C., Pannell, L., Zhang, Y., et al. (1997). Carboxypeptidase $\mathrm{E}$ is a regulated secretory pathway sorting receptor: genetic obliteration leads to endocrine disorders in Cpe(fat) mice. Cell 88, 73-83. doi: 10.1016/S0092-8674(00)81860-7

Coulon, M., Wellman, C. L., Marjara, I. S., Janczak, A. M., and Zanella, A. J. (2013). Early adverse experience alters dendritic spine density and gene expression in prefrontal cortex and hippocampus in lambs. Psychoneuroendocrinology 38, 1112-1121. doi: 10.1016/j.psyneuen.2012.10.018

Deiss, L. P., Feinstein, E., Berissi, H., Cohen, O., and Kimchi, A. (1995). Identification of a novel serine/threonine kinase and a novel $15-\mathrm{kD}$ protein as 
potential mediators of the gamma interferon-induced cell death. Genes Dev. 9, 15-30. doi: 10.1101/gad.9.1.15

Evans, S. J., Choudary, P. V., Neal, C. R., Li, J. Z., Vawter, M. P., Tomita, H., et al. (2004). Dysregulation of the fibroblast growth factor system in major depression. Proc. Natl. Acad. Sci. U.S.A. 101, 15506-15511. doi: 10.1073/pnas. 0406788101

Fan, S., Gao, X., Chen, P., and Li, X. (2018). Carboxypeptidase E-DeltaN promotes migration, invasion and epithelial-mesenchymal transition of human osteosarcoma cell lines through the Wnt/beta-catenin pathway. Biochem. Cell Biol. doi: 10.1139/bcb-2018-0236 [Epub ahead of print].

Feinstein, E., Druck, T., Kastury, K., Berissi, H., Goodart, S. A., Overhauser, J., et al. (1995). Assignment of DAP1 and DAPK-genes that positively mediate programmed cell death triggered by IFN-gamma-to chromosome regions 5p12.2 and 9q34.1, respectively. Genomics 29, 305-307. doi: 10.1006/geno.1995. 1255

Fricker, L. D. (1988). Carboxypeptidase E. Annu. Rev. Physiol. 50, 309-321. doi: 10.1146/annurev.ph.50.030188.001521

Fricker, L. D., and Devi, L. (1993). Posttranslational processing of carboxypeptidase E, a neuropeptide-processing enzyme, in AtT-20 cells and bovine pituitary secretory granules. J. Neurochem. 61, 1404-1415. doi: 10.1111/j.1471-4159. 1993.tb13634.x

Fricker, L. D., and Snyder, S. H. (1983). Purification and characterization of enkephalin convertase, an enkephalin-synthesizing carboxypeptidase. J. Biol. Chem. 258, 10950-10955.

Hook, V. Y., Eiden, L. E., and Brownstein, M. J. (1982). A carboxypeptidase processing enzyme for enkephalin precursors. Nature 295, 341-342. doi: 10. 1038/295341a0

Hook, V. Y., Mezey, E., Fricker, L. D., Pruss, R. M., Siegel, R. E., and Brownstein, M. J. (1985). Immunochemical characterization of carboxypeptidase B-like peptide-hormone-processing enzyme. Proc. Natl. Acad. Sci. U.S.A. 82, 4745-4749. doi: 10.1073/pnas.82.14.4745

Huang, S. M., Mishina, Y. M., Liu, S., Cheung, A., Stegmeier, F., Michaud, G. A., et al. (2009). Tankyrase inhibition stabilizes axin and antagonizes Wnt signalling. Nature 461, 614-620. doi: 10.1038/nature08356

Ibrahim, S. M., Mix, E., Bottcher, T., Koczan, D., Gold, R., Rolfs, A., et al. (2001). Gene expression profiling of the nervous system in murine experimental autoimmune encephalomyelitis. Brain 124, 1927-1938. doi: 10.1093/brain/124. 10.1927

Israsena, N., Hu, M., Fu, W., Kan, L., and Kessler, J. A. (2004). The presence of FGF2 signaling determines whether beta-catenin exerts effects on proliferation or neuronal differentiation of neural stem cells. Dev. Biol. 268, 220-231. doi: 10.1016/j.ydbio.2003.12.024

Ji, L., Wu, H. T., Qin, X. Y., and Lan, R. (2017). Dissecting carboxypeptidase E: properties, functions and pathophysiological roles in disease. Endocr. Connect. 6, R18-R38. doi: 10.1530/EC-17-0020

Jin, K., Graham, S. H., Nagayama, T., Goldsmith, P. C., Greenberg, D. A., Zhou, A., et al. (2001). Altered expression of the neuropeptide-processing enzyme carboxypeptidase $\mathrm{E}$ in the rat brain after global ischemia. J. Cereb. Blood Flow Metab. 21, 1422-1429. doi: 10.1097/00004647-200112000-00006

Jung, Y. K., Kunczt, C. J., Pearson, R. K., Dixon, J. E., and Fricker, L. D. (1991). Structural characterization of the rat carboxypeptidase-E gene. Mol. Endocrinol. 5, 1257-1268. doi: 10.1210/mend-5-9-1257

Koks, S., Luuk, H., Nelovkov, A., Areda, T., and Vasar, E. (2004). A screen for genes induced in the amygdaloid area during cat odor exposure. Genes Brain Behav. 3, 80-89. doi: 10.1046/j.1601-183x.2003.00047.x

Koshimizu, H., Senatorov, V., Loh, Y. P., and Gozes, I. (2009). Neuroprotective protein and carboxypeptidase E. J. Mol. Neurosci. 39, 1-8. doi: 10.1007/s12031008-9164-5

Lee, C., Hu, J., Ralls, S., Kitamura, T., Loh, Y. P., Yang, Y., et al. (2012). The molecular profiles of neural stem cell niche in the adult subventricular zone. PLoS One 7:e50501. doi: 10.1371/journal.pone.0050501

Levy-Strumpf, N., and Kimchi, A. (1998). Death associated proteins (DAPs): from gene identification to the analysis of their apoptotic and tumor suppressive functions. Oncogene 17, 3331-3340. doi: 10.1038/sj.onc.1202588

Liang, C., Carrel, D., Omelchenko, A., Kim, H., Patel, A., Fanget, I., et al. (2018). Cortical neuron migration and dendrite morphology are regulated by carboxypeptidase E. Cereb. Cortex doi: 10.1093/cercor/bhy155 [Epub ahead of print].
Lou, H., Kim, S. K., Zaitsev, E., Snell, C. R., Lu, B., and Loh, Y. P. (2005). Sorting and activity-dependent secretion of BDNF require interaction of a specific motif with the sorting receptor Carboxypeptidase E. Neuron 45, 245-255. doi: 10.1016/j.neuron.2004.12.037

Lou, H., Park, J. J., Cawley, N. X., Sarcon, A., Sun, L., Adams, T., et al. (2010). Carboxypeptidase E cytoplasmic tail mediates localization of synaptic vesicles to the pre-active zone in hypothalamic pre-synaptic terminals. J. Neurochem. 114, 886-896. doi: 10.1111/j.1471-4159.2010.06820.x

Lynch, D. R., Braas, K. M., Hutton, J. C., and Snyder, S. H. (1990). Carboxypeptidase $\mathrm{E}$ (CPE): immunocytochemical localization in the rat central nervous system and pituitary gland. J. Neurosci. 10, 1592-1599. doi: 10.1523/ JNEUROSCI.10-05-01592.1990

MacCumber, M. W., Snyder, S. H., and Ross, C. A. (1990). Carboxypeptidase E (enkephalin convertase): mRNA distribution in rat brain by in situ hybridization. J. Neurosci. 10, 2850-2860. doi: 10.1523/JNEUROSCI.10-0802850.1990

Martinez, A., Otal, R., and Soriano Garcia, E. (2004). [Ephrins, neuronal development and plasticity]. Rev. Neurol. 38, 647-655. doi: 10.33588/rn.3807. 2004068

Martinez, A., and Soriano, E. (2005). Functions of ephrin/Eph interactions in the development of the nervous system: emphasis on the hippocampal system. Brain Res. Brain Res. Rev. 49, 211-226. doi: 10.1016/j.brainresrev.2005.02.001

Mazon Pelaez, I., Vogler, S., Strauss, U., Wernhoff, P., Pahnke, J., Brockmann, G., et al. (2005). Identification of quantitative trait loci controlling cortical motor evoked potentials in experimental autoimmune encephalomyelitis: correlation with incidence, onset and severity of disease. Hum. Mol. Genet. 14, 1977-1989. doi: $10.1093 / \mathrm{hmg} / \mathrm{ddi} 203$

Murphy, M., Drago, J., and Bartlett, P. F. (1990). Fibroblast growth factor stimulates the proliferation and differentiation of neural precursor cells in vitro. J. Neurosci. Res. 25, 463-475. doi: 10.1002/jnr.490250404

Murthy, S. R., Thouennon, E., Li, W. S., Cheng, Y., Bhupatkar, J., Cawley, N. X., et al. (2013). Carboxypeptidase E protects hippocampal neurons during stress in male mice by up-regulating prosurvival BCL2 protein expression. Endocrinology 154, 3284-3293. doi: 10.1210/en.2013-1118

Park, J. J., Cawley, N. X., and Loh, Y. P. (2008). A bi-directional carboxypeptidase E-driven transport mechanism controls BDNF vesicle homeostasis in hippocampal neurons. Mol. Cell. Neurosci. 39, 63-73. doi: 10.1016/j.mcn.2008. 05.016

Pla, V., Paco, S., Ghezali, G., Ciria, V., Pozas, E., Ferrer, I., et al. (2013). Secretory sorting receptors carboxypeptidase $\mathrm{E}$ and secretogranin III in amyloid beta-associated neural degeneration in Alzheimer's disease. Brain Pathol. 23, 274-284. doi: 10.1111/j.1750-3639.2012.00644.x

Qian, Y., Varlamov, O., and Fricker, L. D. (1999). Glu300 of rat carboxypeptidase E is essential for enzymatic activity but not substrate binding or routing to the regulated secretory pathway. J. Biol. Chem. 274, 11582-11586. doi: 10.1074/jbc. 274.17.11582

Qin, X. Y., Cheng, Y., Murthy, S. R., Selvaraj, P., and Loh, Y. P. (2014). carboxypeptidase E-DeltaN, a neuroprotein transiently expressed during development protects embryonic neurons against glutamate neurotoxicity. PLoS One 9:e112996. doi: 10.1371/journal.pone.0112996

Raballo, R., Rhee, J., Lyn-Cook, R., Leckman, J. F., Schwartz, M. L., and Vaccarino, F. M. (2000). Basic fibroblast growth factor (Fgf2) is necessary for cell proliferation and neurogenesis in the developing cerebral cortex. J. Neurosci. 20, 5012-5023. doi: 10.1523/JNEUROSCI.20-13-05012.2000

Rodriguiz, R. M., Wilkins, J. J., Creson, T. K., Biswas, R., Berezniuk, I., Fricker, A. D., et al. (2013). Emergence of anxiety-like behaviours in depressive-like Cpe(fat/fat) mice. Int. J. Neuropsychopharmacol. 16, 1623-1634. doi: 10.1017/ S1461145713000059

Russo, V. C., Gluckman, P. D., Feldman, E. L., and Werther, G. A. (2005). The insulin-like growth factor system and its pleiotropic functions in brain. Endocr. Rev. 26, 916-943. doi: 10.1210/er.2004-0024

Selvaraj, P., Huang, J. S., Chen, A., Skalka, N., Rosin-Arbesfeld, R., and Loh, Y. P. (2015). Neurotrophic factor-alphal modulates NGF-induced neurite outgrowth through interaction with Wnt-3a and Wnt-5a in PC12 cells and cortical neurons. Mol. Cell. Neurosci. 68, 222-233. doi: 10.1016/j.mcn.2015.08.005

Selvaraj, P., Xiao, L., Lee, C., Murthy, S. R., Cawley, N. X., Lane, M., et al. (2017). Neurotrophic Factor-alpha1: a Key Wnt-beta-Catenin Dependent AntiProliferation Factor and ERK-Sox9 activated inducer of embryonic neural stem 
cell differentiation to astrocytes in neurodevelopment. Stem Cells 35, 557-571. doi: $10.1002 /$ stem. 2511

Skalka, N., Caspi, M., Caspi, E., Loh, Y. P., and Rosin-Arbesfeld, R. (2013). Carboxypeptidase E: a negative regulator of the canonical Wnt signaling pathway. Oncogene 32, 2836-2847. doi: 10.1038/onc.2012.308

Song, L., and Fricker, L. (1995). Processing of procarboxypeptidase E into carboxypeptidase E occurs in secretory vesicles. J. Neurochem. 65, 444-453. doi: 10.1046/j.1471-4159.1995.65010444.x

Stahl, S., Reinders, Y., Asan, E., Mothes, W., Conzelmann, E., Sickmann, A., et al. (2007). Proteomic analysis of cathepsin B- and L-deficient mouse brain lysosomes. Biochim. Biophys. Acta 1774, 1237-1246. doi: 10.1016/j.bbapap. 2007.07.004

Strittmatter, S. M., Lynch, D. R., and Snyder, S. H. (1984). $[3 \mathrm{H}]$ guanidinoethylmercaptosuccinic acid binding to tissue homogenates. Selective labeling of enkephalin convertase. J. Biol. Chem. 259, 11812-11817.

Weber, S. J., Louis, R. B., Trombley, L., Bissette, G., Davies, P., and Davis, T. P. (1992). Metabolic half-life of somatostatin and peptidase activities are altered in Alzheimer's disease. J. Gerontol. 47, B18-B25.

Woronowicz, A., Cawley, N. X., Chang, S. Y., Koshimizu, H., Phillips, A. W., Xiong, Z. G., et al. (2010). Carboxypeptidase E knockout mice exhibit abnormal dendritic arborization and spine morphology in central nervous system neurons. J. Neurosci. Res. 88, 64-72. doi: 10.1002/jnr.22174

Woronowicz, A., Cawley, N. X., and Peng Loh, Y. (2012). Carbamazepine prevents hippocampal neurodegeneration in mice lacking the neuroprotective protein, Carboxypetidase E. Clin. Pharmacol. Biopharm. Suppl. 1:2.

Woronowicz, A., Koshimizu, H., Chang, S. Y., Cawley, N. X., Hill, J. M., Rodriguiz, R. M., et al. (2008). Absence of carboxypeptidase $\mathrm{E}$ leads to adult hippocampal neuronal degeneration and memory deficits. Hippocampus 18, 1051-1063. doi: 10.1002/hipo.20462

Xiao, L., Chang, S. Y., Xiong, Z. G., Selveraj, P., and Peng Loh, Y. (2017). Absence of Carboxypeptidase E/Neurotrophic Factor-Alpha1 in Knock-Out Mice Leads to Dysfunction of BDNF-TRKB Signaling in Hippocampus. J. Mol. Neurosci. 62, 79-87. doi: 10.1007/s12031-017-0914-0
Xiao, L., Yang, X., Sharma, V. K., and Loh, Y. P. (2018). Cloning, gene regulation, and neuronal proliferation functions of novel $\mathrm{N}$-terminal-truncated carboxypeptidase E/neurotrophic factor-alphal variants in embryonic mouse brain. FASEB J. 33, 808-820. doi: 10.1096/fj.201800359R

Yang, X., Cong, L., Lou, H., and Loh, Y. P. (2017). A novel 40kDa CPE- $\Delta$ N isoform promotes proliferation and invasion in pancreatic cancer cells. Cancer Res. 77, 1967-1967. doi: 10.1158/1538-7445.AM2017-1967

Zechel, S., Werner, S., Unsicker, K., and von Bohlen und Halbach, O. (2010). Expression and functions of fibroblast growth factor 2 (FGF-2) in hippocampal formation. Neuroscientist 16, 357-373. doi: 10.1177/1073858410371513

Zheng, M., Streck, R. D., Scott, R. E., Seidah, N. G., and Pintar, J. E. (1994). The developmental expression in rat of proteases furin, PC1, PC2, and carboxypeptidase E: implications for early maturation of proteolytic processing capacity. J. Neurosci. 14, 4656-4673. doi: 10.1523/JNEUROSCI.14-08-04656. 1994

Zhou, A., Minami, M., Zhu, X., Bae, S., Minthorne, J., Lan, J., et al. (2004). Altered biosynthesis of neuropeptide processing enzyme carboxypeptidase E after brain ischemia: molecular mechanism and implication. J. Cereb. Blood Flow Metab. 24, 612-622. doi: 10.1097/01.WCB.0000118959.03453.17

Zhu, X., Wu, K., Rife, L., Cawley, N. X., Brown, B., Adams, T., et al. (2005). Carboxypeptidase $\mathrm{E}$ is required for normal synaptic transmission from photoreceptors to the inner retina. J. Neurochem. 95, 1351-1362. doi: 10.1111/ j.1471-4159.2005.03460.x

Conflict of Interest Statement: The authors declare that the research was conducted in the absence of any commercial or financial relationships that could be construed as a potential conflict of interest.

Copyright (c) 2019 Xiao, Yang and Loh. This is an open-access article distributed under the terms of the Creative Commons Attribution License (CC BY). The use, distribution or reproduction in other forums is permitted, provided the original author(s) and the copyright owner(s) are credited and that the original publication in this journal is cited, in accordance with accepted academic practice. No use, distribution or reproduction is permitted which does not comply with these terms. 